\title{
Structural State Scale-Dependent Physical Characteristics and Endurance of Cermet Composite for Cutting Metal
}

\author{
V. E. Ovcharenko 1, 2, a), Yu. F. Ivanov ${ }^{2,3, b)}$, A. A. Mohovikov ${ }^{2, c)}$, \\ $\mathrm{Yu}$ Baohai $^{4, \mathrm{~d})}$, and Yanhui Zhao ${ }^{4, \mathrm{e})}$ \\ ${ }^{1}$ Institute of Strength Physics and Materials Science SB RAS, Tomsk, 634055, Russia \\ ${ }^{2}$ Institute of Heavy-Current Electronics SB RAS, Tomsk, 634055, Russia \\ ${ }^{3}$ National Research Tomsk Polytechnic University, Tomsk, 634050, Russia \\ ${ }^{4}$ Institute of Metal Research, Chinese Academy of Sciences, Wenhua Road 72, 110016, China \\ a) Corresponding author: ovcharenko.ove45@mail.ru \\ b) ivanov.yufi55@mail.ru \\ c) mohovikov.maa28@rambler.ru \\ d) baohai.bhyu@imr.ac.cn \\ e) yanhui.yhzhao@imr.ac.cn
}

\begin{abstract}
A structural-phase state developed on the surface of a $\mathrm{TiC} / \mathrm{Ni}-\mathrm{Cr}-\mathrm{Al}$ cermet alloy under superfast heating and cooling produced by pulse electron beam melting has been presented. The effect of the surface's structural state multimodality on the temperature dependencies of the friction and endurance of the cermet tool in cutting metal has been investigated. The high-energy flux treatment of subsurface layers by electron beam pulses in argon-containing gas discharge plasma serves to improve the endurance of metal cutting tools manifold (by a factor of 6), to reduce the friction via precipitation of secondary $200 \mathrm{~nm}$ carbides in binder interlayers. It is possible to improve the cermet tool endurance for cutting metal by a factor of $10-12$ by irradiating the cermet in a reactive nitrogen-containing atmosphere with the ensuing precipitation of nanosize $50 \mathrm{~nm}$ AlN particles in the binder interlayers.
\end{abstract}

Keywords: $\mathrm{TiC} / \mathrm{Ni}-\mathrm{Cr}-\mathrm{Al}$, microstructures, electron beam, friction factor, endurance for metal cutting

\section{INTRODUCTION}

The quantitative data resulting from the numerical experiments performed to elucidate the effect of multiscale structural levels (as well as that their combinations) both on the deformation and fracture of the cermets under high dynamic loading show new approaches for improving their physical and mechanical characteristics. These approaches are based on the feasibility of generating multi-scale structures in the cermet [1], implying that most of them will inevitably be involved in the deformation, and thus serve to change the dominating mechanisms of the main crack's nucleation and growth. In other words, the nucleation, the successive development and propagation of the crack tip in a "mesoscopically" undamaged material is changed for generating meso-damages in the vicinity of the microcrack tip, which then may grow together into a main crack [2]. Such a mechanism is believed to take essentially more time before fracturing occurs, hence it improves the cermet's fracture toughness.

Generating extra structural levels in the surface layer of a cermet is possible via using superfast heating, and thus creating a structural non-equilibrium state which would then be maintained during superfast cooling [3].

In this present work, the cermet samples were modified by pulse electron beam melting. The structures modified this way as well as the effect of subsurface structural-phase state on the physical properties and the effect of subsurface structural-phase state on the physical properties and endurance of the cermet were investigated.

International Conference on Physical Mesomechanics of Multilevel Systems 2014

AIP Conf. Proc. 1623, 455-458 (2014); doi: 10.1063/1.4901495

(C) 2014 AIP Publishing LLC 978-0-7354-1260-6/\$30.00 


\section{EXPERIMENTAL}

Experiments have been carried out on cermet samples composed of $50 \%$ of $\mathrm{TiC}$ particles and $50 \%$ of $(\mathrm{Ni}-\mathrm{Cr}-$ Al)-binder. The parameters of pulse electron beam treatment were as follows: the thickness of the heated cermet layer $-200 \mu \mathrm{m}$, heating rate $-10^{4}$ to $10^{9} \mathrm{~K} / \mathrm{s}$, pulse durations $-\tau=50,100,150,200 \mu \mathrm{s}$, power density $-W_{\mathrm{S}}$ $6 \cdot 10^{5} \mathrm{Wt} / \mathrm{cm}^{2}$, which resulted in the energy density $E_{s}$ of up to $60 \mathrm{~J} / \mathrm{cm}^{2}$, electron beam diameter-1 to $2 \mathrm{~cm}$ [9]. Modified microstructures were examined using a scanning electron microscope (SEM, Philips 515) and a transmission electron microscope (TEM, EM-125).

\section{RESULTS AND DISCUSSION}

\section{Surface Layer Structural Modification Using Pulse Electron Beam Melting}

Cmpacted cermet samples consisted of three base components: (i) the metallic binder reinforced by (ii) brittle, high-hardness TiC particles of mesoscopic scale (1 to $10 \mu \mathrm{m}$ in size), and (iii) the particle/binder interface region of variable composition and a crossover section of up to $4 \mu \mathrm{m}$ in diameter.

Numerical experiments were carried out to determine the temperature fields generated on the surface of the $50 \%$ vol. TiC/50\%vol. (Ni-Cr-Al) cermet under exposure to pulse electron beam melting [10]. These experiments enabled us to estimate the beam power density ranges, pulse durations and repetitions suitable for planning an experiment on determining the effect of these process parameters on the structural-phase state of the cermet subsurface after electron beam melting. The main criteria for obtaining the estimations were (i) the heat penetration depth $(x=100$ to $200 \mu \mathrm{m})$, and (ii) the single pulse heating temperature at the minimal temperature gradient in a layer (up to $3000 \mathrm{~K}$ ). Assuming these criteria, we obtain beam energy density $E_{s}=40-50 \mathrm{~J} / \mathrm{cm}^{2}$ and pulse duration $t_{i}=100-200 \mu \mathrm{s}$. It is necessary, however, to take into account the fact that the temperature profile generated by the first pulse virtually does not depend on the pulse number. The pulse number allows for controlling the cermet's phases' interaction time under the non-equilibrium temperature-time conditions for the specified energy densities and pulse durations.

The microstructures in the cermet's subsurface generated by electron beam irradiation at the energy density of $40 \mathrm{~J} / \mathrm{cm}^{2}$ and pulse durations of 50, 100, 150 and $200 \mu \mathrm{s}$, respectively, are shown in Fig. 1. The shortest pulse duration $(50 \mu \mathrm{s})$ was able to generate a vitreous structure layer on the cermet's surface (see Fig. 1(a)) with almost all carbide particles dissolved in the melted binder. Increasing pulse duration to $100 \mu$ s or even more (to 150 and $200 \mu \mathrm{s})$ resulted in reducing the degree of the carbide particles' dissolubility. Also the coarsest TiC particles showed cracks, which were then filled with the binder. The inter-particle binder layers contained secondary phases being inherent to superquickly solidified multiphase metallic systems (see Fig. 2(c, d)).

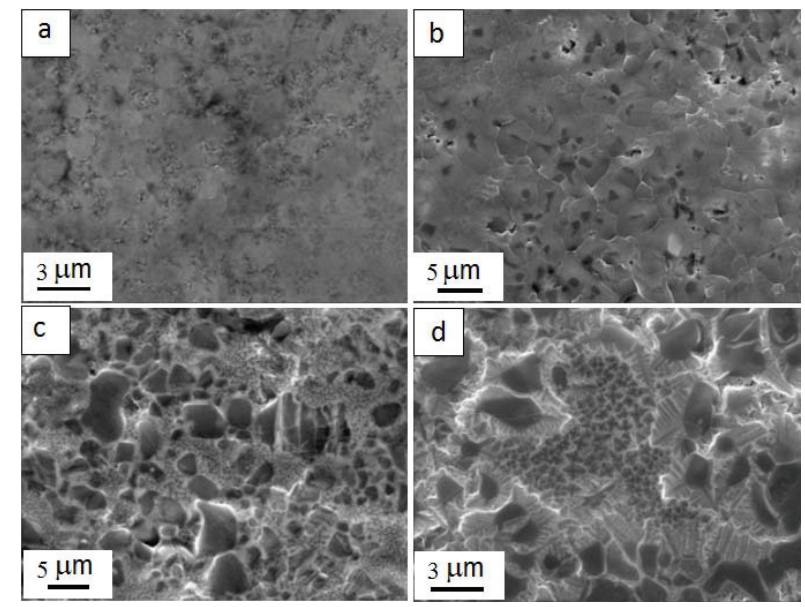

FIGURE 1. SEM images of the pulse electron beam irradiated cermet. The irradiation parameters are as follows: beam energy density $40 \mathrm{~J} / \mathrm{cm}^{2}, 15$ pulses, pulse repetition rate $1 \mathrm{~s}^{-1}$, pulse duration 50 (a), 100 (b), 150 (c) and $200 \mu \mathrm{s}$ (d) 

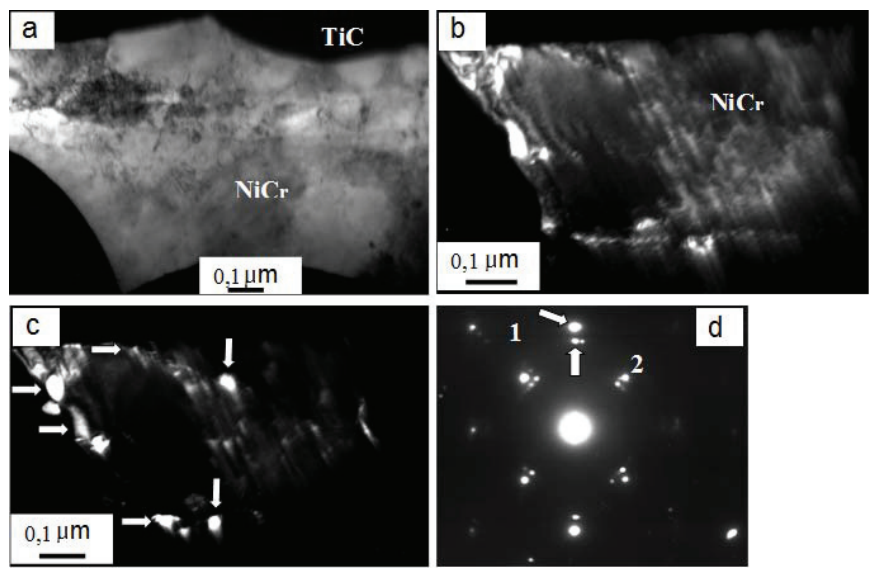

FIGURE 2. TEM images of $\mathrm{TiC} /(\mathrm{Ni}-\mathrm{Cr}-\mathrm{Al})$ irradiated cermet. The irradiation parameters are as follows: beam energy density $40 \mathrm{~J} / \mathrm{cm}^{2}$, pulse duration $200 \mu \mathrm{s}(\mathrm{d}) ;(\mathrm{a}, \mathrm{b})$ bright field images, (c) dark field image using [022] Ni(Cr-Al) and [022]TiC reflections, respectively, and (d) SAED image of image (a). Arrows show: TiC carbide particles in image (b); dark field reflections: 1 occurrence for image (b), 2 occurrences for image (c)

The TEM images allow examining the modified structural-phase state of the cermet subsurface in greater detail. It has been found that electron beam irradiation of cermet by 150 to $200 \mu$ s pulses is characterised mainly by carbide dissolution and the subsequent precipitation of secondary 60 to $75 \mu \mathrm{m}$ carbides in the inter-particle binder layers (Fig. 2).

As can be seen from Fig. 2, an extra structural component composed of nanosize secondary TiC carbide particles dispersed in the inter-particle binder layers is formed when exposing the $\mathrm{TiC} / \mathrm{Ni}-\mathrm{Cr}-\mathrm{Al}$ cermet to pulse electron beam melting at the pulse durations of 150 to $200 \mu \mathrm{s}$ and the power density of 8 to $10 \cdot 10^{5} \mathrm{~W} / \mathrm{cm}^{2}$. After pulse electron beam melting, a four-level structure consisting of (a) primary TiC particles, (b) inter-particle binder layers, (c) particle/binder interface region, and (d) secondary nanosized carbide precipitations is embedded in the interparticle binder layers on the surface of the cermet.

Also, we show elsewhere [4] that the fifth structural level appears in the cermet after pulse electron beam melting in nitrogen-containing gas discharge plasma. The metallic binder on the surface of such a cermet contains some aluminum nitride particles of about $50 \mathrm{~nm}$ in size (see Fig. 3).
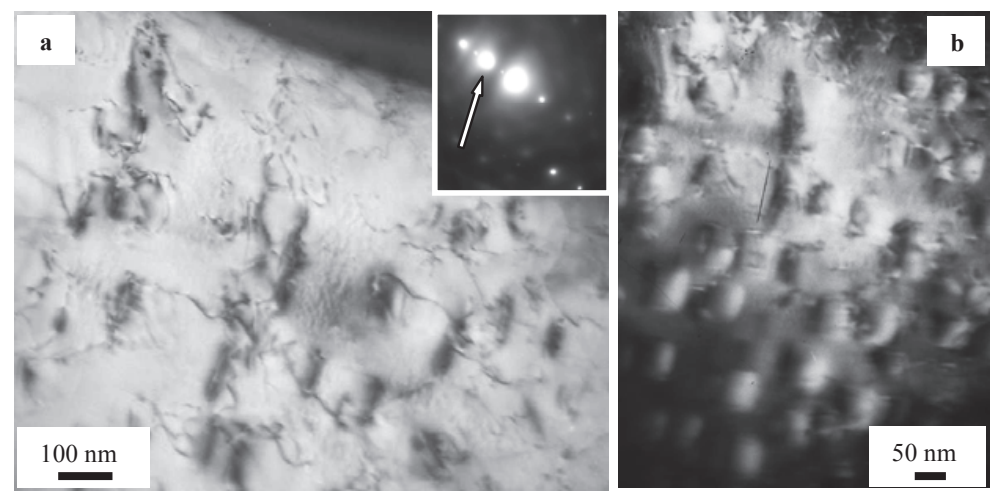

FIGURE 3. TEM images of cermet under electron beam treatment in nitrogen-containing gas discharge plasma:

(a) right field image, (b) dark field image using coinciding reflections [002] $\mathrm{Ni}+[102] \mathrm{AlN}$ and

(c) SAED image using reflection shown by the arrow 

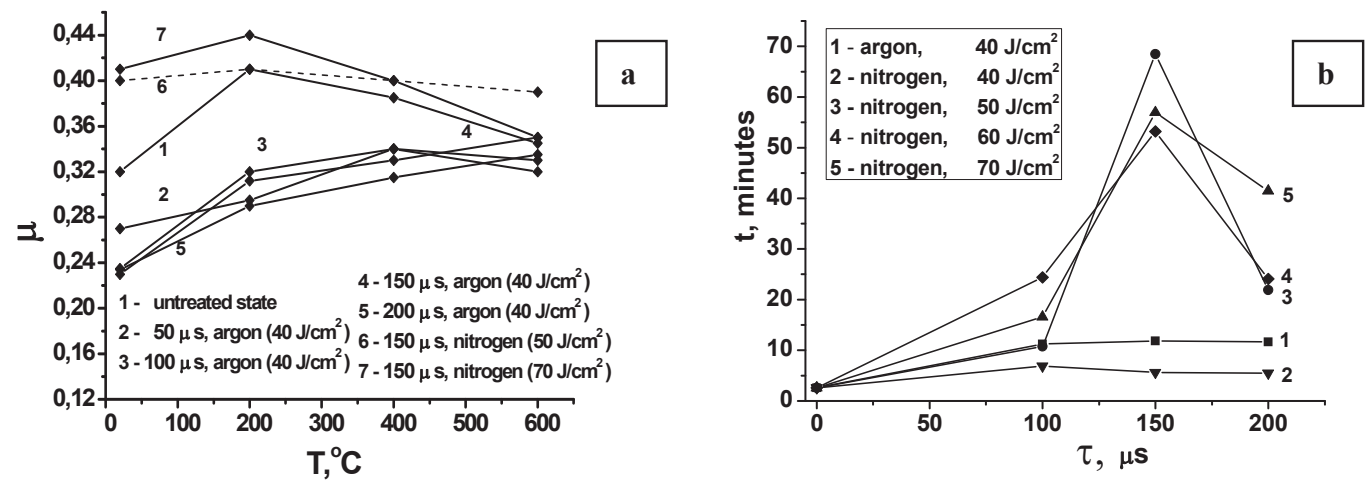

FIGURE 4. Temperature dependencies of the friction factor: (a) cermet for cutting metal and (b) the endurance of the cermet tool as a function of pulse duration for different electron beam energy densities. 1 - untreated state, 2-5-electron beam melting in argon-containing gas discharge plasma, 6, 7-electron beam melting in nitrogen-containing gas discharge plasma

\section{Effect of Subsurface Structural-Phase State on the Physical Properties and Endurance of the Cermet}

Temperature dependencies of the friction factor of the cermet doing metal cutting (Fig. 4(a)) are shown together with the endurance of the cermet cutting tool as the functions of the pulse duration and energy density (Fig. 4(b)). It can be seen that the friction factor of the cermet employed in cutting metal increases with the temperature of samples 2 to 5 (treated in argon-containing gas discharge plasma) to a much lesser extent than does the untreated sample and samples 6 to 7 (treated in nitrogen-containing gas discharge plasma). This may be attributed to coarsest TiC particles and cracks in the modified subsurface microstructure treated by nitrogen-containing gas discharge plasma (see Fig. 1(c, d)). However, in case of the cermet treated by argon-containing gas discharge plasma, the vitreous structure layer with all carbide particles being dissolved in the melted binder will be responsible for the reduced friction factor. The untreated cermet sample 1 is characterized by three structural levels. Samples 2 to 5 treated in argon-containing gas discharge plasma offer four structural levels. Five structural levels are found in the samples treated in nitrogen-containing gas discharge plasma. From comparing the curves in Fig. 4, it can be concluded that the temperature dependencies of friction as well as the endurance while cutting metal are in a direct relation to the number of structural levels generated in the subsurface of the cermet platelet. The higher the number of structural levels in the subsurface of the cermet, the more moderate the influence of the temperature on the friction is. Electron beam melting in nitrogen-containing gas discharge plasma at $50 \mathrm{~J} / \mathrm{cm}^{2}$ does not result in any sufficient effect of the temperature on the friction, while the temperatures reach $600^{\circ} \mathrm{C}$ (Fig. $4(\mathrm{a})$ ). Increasing the number of structural levels in the subsurface of a cermet has a good effect on improving the cutting endurance of the tool. An improvement by a factor of 12 and higher is achieved as compared to the untreated cermet (Fig. 4(b)).

\section{CONCLUSION}

By the example of $\mathrm{TiC} /(\mathrm{Ni}-\mathrm{Cr}-\mathrm{Al})$ cermet we show that by generating extra structural levels in the subsurface of the cermet, we can reduce the temperature dependence of friction and improve the endurance of a cutting tool for metal by multiple times. In other words, by purposefully introducing a hierarchy of structural levels in the subsurface, we can improve the cermet's adequate response to the changed external conditions and provide for a long life of the cermet tool under extreme service conditions.

\section{REFERENCES}

1. S. G. Psakhie, V. E. Ovcharenko, A. G. Knyazeva, and E. V. Shilko, Fiz. Mezomekh. 14(6), 23 (2011).

2. O. Raddatz, G. A. Schneider, W. Machens, H. Vob, and N. Claussen, J. Eur. Ceram. Soc. 20, 2261 (2000).

3. V. E. Ovcharenko, B. H. Yu, and S. G. Psakhie, Mater. Sci. Technol. 21(3), 429 (2005).

4. B. H. Yu, V. E. Ovcharenko, S. G. Psakhie, and O. V. Lapshin, J. Mater. Sci. Technol. 22(4), 511 (2006). 